УДК 316.75

\title{
ДОВЕРИЕ КАК ФОРМА ПОДДЕРЖКИ СОЦИАЛЬНЫХ ИНСТИТУТОВ
}

\author{
T.А. Гужавина \\ (https://orcid.org/0000-0003-0636-7690), \\ Вологодский научный изентр РАН, Вологда, Россия, \\ e-mail:tanja_gta@mail.ru
}

\section{DOI: 10.14258/ssi(2019)4-03}

В фокусе статьи - доверие, раскрывающее отношение респондентов к окружающим (межличностное) и к социальным институтам (институциональное). Цель статьи - показать на эмпирическом материале распределение доверия между группами респондентов, выделенными на основе рассчитанного индекса доверия, взаимосвязь межличностного и институционального доверия, а также влияние на его формирование факторов макро- и микроуровня. Новизна работы заключается в использовании для анализа интегрального индекса доверия, включающего в себя индексы межличностного доверия и институционального доверия. Оба индекса носят комплексный характер и рассчитывались по каждому респонденту. В ходе анализа конструировались группы по уровню доверия. Было выявлено влияние на доверие факторов социализирующего и институционального характера. Установлено, что уровень доверия оказывает влияние на отношение к существующим политическим институтам. Понимание механизма формирования доверия, выявление влияющих на него факторов дает возможность выстраивать социальную политику, принимать управленческие решения.

Ключевые слова: доверие, межличностное доверие, институцииональное доверие, индекс доверия, соичильные институтьл.

\section{TRUST AS A FORM OF SUPPORT FOR SOCIAL INSTITUTIONS}

\section{T.A. Guzhavina \\ Vologda Scientific Center of the Russian Academy of Sciences, Vologda, Russia, e-mail: tanja_gta@mail.ru}

Trust is a basis of social relations, is a constant object of research attention. It is influenced by many different factors of endogenous and exogenous nature. The focus of the article is trust, revealed as the respondents' attitude to others (interpersonal trust) and attitude to social institutions (institutional). Against the backdrop of a trend of declining confidence recorded by many large research companies (FOM), the analysis of the reasons that help trust is important. It is important to 
understand what factors and mechanisms form trust, and how it affects social institutions. The paper presents the results of a study obtained by specialists of the VolNC RAS. Interpretation of trust is carried out on the basis of existing theoretical and methodological approaches. An indicator method was used for the analysis and grouping data. The novelty of the work is the use of an integral index. The integral index of trust was calculated on the base of particular indices of interpersonal trust and institutional trust. Both indices are complex and calculated for each respondent. The study revealed the influence of factors of a socializing and institutional nature on trust. It is established that the level of trust influences the attitude to existing political institutions. The purpose of this article is to show by means of empirical material the distribution of trust between groups of respondents identified on the basis of the calculated confidence index, the relationship of interpersonal and institutional trust, as well as the influence of macro and micro level factors on its formation.

Keywords: trust, interpersonal trust, institutional trust, confidence index, social institutions.

\section{Введение}

Трансформация современного общества привела к изменениям во взаимоотношениях власти и общества, сделав их менее определенными и, что более важно, менее прогнозируемыми. Неспособность эффективно справляться с растущим экономическим и социальным неравенством, массовой миграцией, экологическими и техногенными угрозами, демографическими и другими проблемами современного общества стала причиной разочарования в деятельности государственных институтов. Тем не менее критика правящего режима не становится основой консолидации граждан. Доказательство тому - то, что яркие публичные фигуры протестного движения не стали признанными лидерами общественного мнения. Общественные интересы по-прежнему артикулируются государственными институтами. В совокупности эти факторы продуцируют снижение уровня доверия почти всем институциональным структурам. В данной ситуации просматривается явное противоречие, формулирующее вопрос о характере отношений власти и общества в сегодняшней России, о наличии доверия и его запасе в российском социуме.

В научном и общественном дискурсе мнение относительно значительного влияния доверия на экономическое развитие, рост благосостояния, функционирование структур гражданского общества является устоявшимся (Кертман, 2006; Шабунова, 2015). Оно обеспечивает и поддерживает устойчивость и интегрированность общества, прежде всего через важнейшие экономические процессы: инвестиции, сбережение, кредитование, фондовую деятельность, акционирование и т.д. Будучи явлением, кажущимся нам самоочевидным, естественным, не нуждающимся в специальном обосновании, доверие, тем не менее, по сути своей продукт, формирующийся в границах определенного исторического периода под влиянием различных культурных контекстов. Представляя собой сложный феномен, доверие 
характеризуется структурностью и функциональностью, базирующимися на разных смысловых основаниях. Оно имеет разностороннюю направленность с точки зрения объекта доверия. Эти свойства доверия позволяют ему влиять на процессы взаимодействия в политике и экономике, в организациях и в различных группах (профессиональных, территориальных, этнических, социально-экономических, организационных). Отсюда и интерес к доверию со стороны различных отраслей знания, что подчеркивает многоаспектность данного явления.

Раскрывая сущность доверия, исследователи выделяют различные его основания. А. Селигмен видит доверие как следствие «...ролевой неопределенности, связанной со структурной непрозрачностью ролей, в ситуации, когда системно определенные ожидания больше не жизнеспособны» (Селигмен, 2002). У Н. Лумана доверие предстает как необходимое условие общественного развития, поскольку происходит увеличение сложности и непрозрачности современного общества, что ведет к нарастанию неуверенности у людей. Без системного доверия, считает ученый, экономическая, правовая, политическая системы не смогут стимулировать необходимую деятельность в ситуации неопределенности или риска. Понимание доверия как символического кредита и необходимого, по сути, атрибутивного условия интеракции субъектов составляет главное содержание принципов генерализованного обмена (безусловности) в современном обществе. В то время как угасание доверия, понятого как ролевые ожидания, составляет новый вид риска (Luhman, 2000).

С трактовкой роли доверия на институциональном уровне Н. Лумана перекликается и характеристика выделенного Э. Гидденсом абстрактного доверия. Данный тип доверия - продукт «позднего модерна». В зоне абстрактного доверия - правительство, страхование, банковские операции, принципы демократии, научное или профессиональное знание и т.п. Логика рассуждений Э. Гидденса позволяет понять, что поле доверия охватывает политические и экономические отношения, институты и организации, т.е. весь социальный порядок (Гидденс, 2011). Саму сущность доверия ученый понимает как связь веры и уверенности (Гидденс, 2011). Э. Гидденс выделил и персонифицированное, или межличностное, доверие, которое выполняет важнейшую функцию в обществе, обеспечивая ощущение надежности повседневных отношений.

Известный исследователь доверия П. Штомка определяет его как «,,залог“ (уверенность и опирающиеся на него действия), свидетельствующий о том, что неопределенные будущие действия других людей или функционирование оборудования либо учреждения будут нам полезны» (Штомпка, 2012). Он выделяет в качестве структурных характеристик доверия его вертикальную и горизонтальную формы (Штомпка, 2012). Категория «вертикальное доверие» характеризует систему отношений между партнерами, находящимися на разных уровнях социальной иерархии. Так он понимает доверие граждан власти, контролирующей действия людей (легитимность власти). Но, с другой стороны, власть должна оправдать доверие к себе. Достигается это с помощью избирательной системы, через подтверждение срока полномочий со стороны граждан.

Влияние культурной составляющей на доверие мы находим в исследованиях Ф. Фукуямы. Вырабатываемые в культуре того или иного сообщества нор- 
мы становятся основанием взаимодействия его членов. Опора на нормы создает, в свою очередь, ожидание того, что другие члены сообщества «будут вести себя более или менее предсказуемо, честно и со вниманием к нуждам окружающих, в согласии с некоторыми общими нормами» (Фукуяма, 2004). Данное ожидание и становится основанием доверия. В контексте влияния на экономические отношения трактует доверие К. Эрроу. «Доверие и подобные ему вещи, такие как преданность или правдивость, пример того, что экономисты называют «внешними условиями». Это товар, у него есть реальная экономическая и практическая ценность; он повышает эффективность системы в целом, позволяет вам производить больше благ или чего-то другого, что вы считаете ценностью. Но он не относится к тем товарам, торговля которыми на рынке технически осуществима или вообще осмыслена» (Arrow,1974). Фактически, отмечает ученый, каждая сделка содержит в себе элемент доверия, а большая часть экономических проблем, и в первую очередь отсталости, в значительной степени объяснима недостатком взаимного доверия.

Интерес к доверию присутствует и в отечественной науке. Ученые отмечают такие его характеристики, как системность, способность поддерживать устойчивость общества, выступить условием возникновения различных ассоциаций (Давыденко, Ромашкин, 2011). Доверие в постсоветской России Л. Гудков интерпретирует как «сложный социальный феномен (закрытое социальное взаимодействие), структура которого представляет собой соединение разных смысловых оснований... соответственно, определяется разными нормами ожидания и характера исполнения действия. Но во всех этих случаях имеет место предпонимание ситуации (ее определение и схематизация действия), то есть актуализация горизонтов действия и возможных способов поведения своего и партнера» (Гудков, 2012).

Исследователи доверия сходятся в понимании присутствия в обществе двух его основных видов: межличностного и институционального (Гидденс, 2011; Глушко, 2014; Заболотная, 2003; Гужавина, 2012). При этом большая часть публикаций обращена на такую его форму, как институциональное, или обезличенное доверие. Межличностное доверие чаще рассматривается как психологическое явление (Алексеева, 2008; Антоненко, 2012; Ильин, 2013; Татарко, 2014; Купрейченко, 2008). Оно характеризуется как основополагающее, как лежащее в основе человеческого взаимодействия. Это связано с тем, что носителем доверия является отдельный индивид. Доверие служит как значимый социальный ресурс, обеспечивая индивиду возможность взаимодействия с окружающими. Можно утверждать, что без доверия невозможно общество как таковое.

Характерной чертой современности можно считать необходимость для индивидов значительного числа контактов, которые становятся все более и более кратковременными. Это порождает определенные риски во взаимоотношениях между акторами, поскольку они не успевают получить достаточного количества информации и тем более оценить характер, репутацию, компетентность своих контрагентов. Доверие чрезвычайно востребовано и в ситуациях, которые невозможно полностью контролировать (Coleman, 1990). 
Теоретические взгляды на доверие, существующие в отечественной и зарубежной науке, позволили нам сформулировать некоторые тезисы, ставшие основанием исследования. Во-первых, социальные отношения основаны на доверии, что проявляется в установках индивидов на взаимодействие с окружающими. Во-вторых, доверие, проявляясь в сфере межличностных взаимодействий и отношений, выступает и как ресурс, и как принцип их конструирования, и как особый вид социальных отношений. В-третьих, доверие рассматривается как продукт социализирующего воздействия агентов и институтов. В-четвертых, обеспечение социального порядка в обществе достигается за счет доверия социальным организациям и институтам, нормам и правилам, создаваемым и поддерживаемым ими. В-пятых, межличностное доверие представляет собой основу для формирования институционального доверия, связь между которыми имеет принципиальное значение.

\section{Результаты исследования}

Цель данной статьи - показать на эмпирическом материале взаимосвязь межличностного и институционального доверия, а также влияние на его формирование факторов макро- и микроуровня; показать его неравномерное распределение в обществе между различными группами респондентов. Источником информации для данной статьи стали результаты исследования, проведенного в рамках реализованного при поддержке РФФИ проекта «Региональный социальный капитал в условиях кризиса». Объем выборки составляет 1500 человек. Опрашивались жители области старше 18 лет. Выборка целенаправленная, квотная. Репрезентативность выборки обеспечивается следующими условиями: соблюдение пропорций между городским и сельским населением; пропорций между жителями населенных пунктов различных типов (сельские населенные пункты, малые и средние города); половозрастной структуры взрослого населения области. Опрос проводился в 2016 г.

Для оценки состояния доверия и анализа его влияния на характер социальных отношений использовался интегральный индекс, который рассчитывался из двух совокупных индексов - межличностного и институционального доверия, каждый из которых, в свою очередь, состоял из двух индексов. Индекс межличностного доверия состоит из индекса доверия близкому окружению, рассчитанного как средняя величина индексов доверия родственникам, близким, друзьям, коллегам, знакомым и т.д., и индекса доверия дальнему окружению, рассчитанного как среднее индексов доверия людям, представителям профессиональных групп (врач, учитель, воспитатель детсада, полицейский, госслужащий-чиновник и пр.). Индекс институционального доверия рассчитан как среднее индексов уровня доверия политическим институтам (президент и другие органы власти, политические партии, выборы и пр.) и индекса доверия социальным институтам, рассчитанного как средняя величина частных индексов доверия СМИ, правоохранительным органам, суду, армии, церкви и т.п. Индексы рассчитывались по каждому респонденту.

На основании расчетных индексов все респонденты были разбиты на четыре группы в зависимости от уровня доверия. Люди с самым низким уровнем доверия, которые при ответе на вопросы анкеты в основном выбирали позицию «не дове- 
ряю», были включены в первую группу. По нашим расчетам группа составила 16,1\%. Во вторую группу вошли те, кто в большинстве своем выбирали альтернативу «скорее не доверяю». Их доля составила 28,5\%. Людей «скорее доверяющих» в области 41,3\%. Максимально возможный уровень доверия продемонстрировали $14,1 \%$.

Использование данной методики дает нам возможность оценить роль и значение целого ряда факторов для формирования и поддержания доверия. Данные факторы мы относим как к макро-, так и к микроуровню. На макроуровне представлены внутриполитические факторы, характеризующие политический и экономический курс правительства, осознание гражданами проводимой ими политики и оценка социального самочувствия. Здесь мы встречаемся с эндогенным и рациональным характером доверия (Dasgupta,1988; Orren, 1995). Успешная политика порождает доверие, неуспешная - снижает его уровень. На микроуровне представлены факторы, оказывающие влияние на социализацию индивида: пол, возраст, образование, место проживания, доход семьи и т.д., т.е. то, что в совокупности формирует индивидуальный жизненный опыт человека.

Чаще всего в исследованиях оценивается общее состояние доверия, которое позволяет распределить респондентов, позиционирующих себя в диапазоне от не доверяющих до доверяющих большинству или всем (табл. 1).

Таблица 1

Распределение ответов на вопрос «Кому можно доверять, на Ваш взгляд, в наше время?», процент от числа ответивших

\begin{tabular}{l|c}
\multicolumn{1}{c|}{ Вариант ответа } & \\
\hline Никому нельзя доверять & 21,5 \\
\hline Только самым близким друзьям и родственникам & 56,4 \\
\hline Большинству знакомых людей можно доверять & 15,7 \\
\hline Большинству людей или всем людям без исключения можно доверять & 6,1 \\
\hline Опрос «Региональный социальный капитал в условиях кризиса». Июнь 2016 г. &
\end{tabular}

Получаемая таким образом информация говорит об ограниченном радиусе доверия, об ориентации на так называемое кровно-родственное доверие (Кученкова, 2016) Однако имеющиеся данные дают весьма приблизительное представление о реальном доверии. Фактически доверие значительно шире. Это связано с тем фактом, что в реальной жизни любому человеку приходится контактировать со значительным количеством людей, которые встречаются ему впервые (покупатели в магазине, горожане на массовом мероприятии, пассажиры в транспорте и т.д.). Подобные контакты носят чаще всего визуальный характер, но могут приобрести иной характер в случае изменения ситуации. Однако нас интересуют более глубокие процессы, связанные с состоянием доверия. Такую возможность дает нам анализ доверия на основе интегрального индекса (табл. 2).

Полученные на основе индекса доверия данные показывают более глубокую дифференциацию доверия среди респондентов. Более заметны крайние позиции. 
Распределение ответов на вопрос

«Насколько Вы доверяете или не доверяете людям, находящимся вместе с Вами в общественных местах (магазин, почта, автобус и т.п.)?», процент от числа ответивших, в зависимости от уровня доверия

\begin{tabular}{l|c|c|c|c}
\multicolumn{1}{c}{ Вариант ответа } & \multicolumn{4}{c}{ Типы доверия } \\
\cline { 2 - 5 } & $\mathbf{1}$ & $\mathbf{2}$ & $\mathbf{3}$ & $\mathbf{4}$ \\
\hline Полностью и в основном доверяю & 1 & 11 & 21 & 54 \\
\hline В основном не доверяю & 32 & 41 & 27 & 17 \\
\hline Полностью не доверяю & 61 & 24 & 11 & 2 \\
\hline Затрудняюсь ответить & 6 & 25 & 41 & 28 \\
\hline
\end{tabular}

Опрос «Региональный сочииальньй капитал в условиях кризиса». Июнь 2016 г.

Различия в уровне доверия во многом определяются социализирующими факторами, такими как возраст, пол, образование (табл. 3-5).

Таблица 3

Распределение населения по группам доверия

в зависимости от возраста, процент от числа ответивших

\begin{tabular}{c|c|c|c|c|c|c|c|c}
\multirow{2}{*}{$\begin{array}{c}\text { Уровень } \\
\text { доверия }\end{array}$} & \multicolumn{10}{c}{ Возраст } \\
\cline { 2 - 9 } & $\mathbf{1 8 - 2 1}$ & $\mathbf{2 2 - 2 5}$ & $\mathbf{2 6 - 3 0}$ & $\mathbf{3 1 - 3 5}$ & $\mathbf{3 6 - 4 5}$ & $\mathbf{4 6 - 5 5}$ & $\mathbf{5 6 - 6 5}$ & старше 65 \\
\hline 1 & 13 & 15 & 17 & 15 & 16 & 18 & 19 & 9 \\
\hline 2 & 18 & 25 & 32 & 30 & 27 & 27 & 33 & 25 \\
\hline 3 & 45 & 43 & 41 & 40 & 37 & 42 & 38 & 55 \\
\hline 4 & 25 & 17 & 10 & 15 & 20 & 13 & 10 & 11 \\
\hline
\end{tabular}

Опрос «Региональный сочиальный капитал в условиях кризиса». Июнь 2016 г.

Более высокий уровень доверия демонстрируют молодые люди, а также респонденты из возрастной когорты. В первом случае это связано с юношеским взглядом на жизнь, наличием поддержки со стороны семьи, устремленностью в будущее. С возрастом в данную установку вносятся коррективы, и жизненный опыт приводит к снижению данного показателя. Наименьшего уровня он достигает в возрастной группе 56-65 лет. Эта группа включает в себя людей, оказавшихся в ситуации перехода от периода высокой жизненной активности в пенсионный период. Данный переход у значительного большинства связан с трудностями социализации, адаптацией к новому статусу, снижением уровня жизни. 
Распределение населения по группам доверия в зависимости от образования, процент от числа ответивших

\begin{tabular}{c|c|c|c|c} 
Группы & $\begin{array}{c}\text { Начальное или } \\
\text { восьмилетнее }\end{array}$ & Среднее & $\begin{array}{c}\text { Среднее } \\
\text { специальное }\end{array}$ & Высшее \\
\hline 1 & 15 & 19 & 16 & 14 \\
\hline 2 & 29 & 32 & 27 & 28 \\
\hline 3 & 48 & 38 & 43 & 40 \\
\hline 4 & 9 & 11 & 14 & 18 \\
\hline
\end{tabular}

Опрос «Региональный соияиальный капитал в условиях кризиса». Июнь 2016 г.

Образовательный статус демонстрирует свое непосредственное влияние как фактор формирования доверия прежде всего в группе с высоким уровнем доверия. Хотя следует отметить, что действие данного фактора неоднозначно. Получаемая индивидом информация может оказывать самое разнонаправленное влияние. Однако более высокий уровень образования позволяет ее критичнее воспринимать, особенно в свете распространения значительного количества фейковых новостей.

Таблица 5

Распределение населения по группам доверия

в зависимости от места проживания, процент от числа ответивших

\begin{tabular}{c|c|c} 
Группы & В городе & $\begin{array}{c}\text { В сельской } \\
\text { местности }\end{array}$ \\
\hline 1 & 17 & 14 \\
\hline 2 & 28 & 29 \\
\hline 3 & 38 & 51 \\
\hline 4 & 17 & 6 \\
\hline
\end{tabular}

Опрос «Региональный сочиильный капитал в условиях кризиса». Июнь 2016 г.

Городские условия жизни оказывают более сильное позитивное влияние на доверие, как ни парадоксально на первый взгляд. Горожане в большей степени представлены в группе с высоким уровнем доверия (табл. 5). Возможно, опыт городской жизни, где мы чаще встречаем незнакомцев, дает нам больше опыта взаимодействия с ними, что в определенной степени снижает межличностную напряженность и формирует склонность доверять окружающим. Опыт сельской жизни, когда практически все знают друг друга, в большей степени ориентирует на особенности характера и поведения, что и усиливает, на наш взгляд, уровень недоверия.

Как видим, социализирующие факторы оказывают непосредственное влияние на формирование доверия, однако признать его однозначным нельзя. Они скорее 
говорят о сложности данного процесса, его многовариантности, свидетельствуют о наличии эндогенных факторов.

Доверие на макроуровне проявляет себя в доверии институтам. Здесь мы в большей степени встречаемся с рациональным характером доверия. На данный признак доверия указывают многие исследователи (Shepsle, 1995, Stark, 1995). Они отмечают, что доверие институтам связано с пониманием индивидами эффективности их деятельности, которые тем самым генерируют доверие.

Среди исследователей отмечается наличие доверия прежде всего тем институтам, которые успешно проводят политику по устранению ограничений свободы личности, обеспечению демократических прав и свобод, борьбе с коррупцией (Diamond, 1999).

В нашем исследовании наблюдалось доверие основным политическим институтам. К их числу относятся на федеральном уровне президент, правительство, парламент, на региональном уровне - губернатор, законодательное собрание области, правительство области. Значение этих институтов велико и внимание к их деятельности значительное. Они определяют вектор развития страны в условиях глубокой трансформации российского общества. В этих условиях власти приходится принимать порой крайне непопулярные решения, что сказывается на уровне доверия со стороны населения.

В рамках статьи нет возможности представить анализ по всем указанным институтам. Однако тенденции в отношении них схожи. В связи с этим рассмотрим в качестве примера только два из них, являющихся наиболее влиятельными на уровне страны и на уровне региона. Это институты президента и губернатора. Особенностью данных институтов является их яркая персонализация, что также оказывает влияние на формирование доверия к данным институтам. Здесь, на наш взгляд, в большей степени проявляется и фактор межличностного доверия, чем по отношению к другим институтам.

Наиболее влиятельным политическим институтом в стране является институт президента (табл. 6).

Таблица 6

Распределение ответов на вопрос

«Насколько Вы доверяете или не доверяете Президенту РФ?», процент от числа ответивших

\begin{tabular}{l|c|c|c|c}
\multirow{2}{*}{\multicolumn{1}{c}{ Вариант ответа }} & \multicolumn{5}{|c}{ Типы доверия } \\
\cline { 2 - 5 } & $\mathbf{1}$ & $\mathbf{2}$ & $\mathbf{3}$ & $\mathbf{4}$ \\
\hline Полностью доверяю & 4 & 8 & 14 & 33 \\
\hline Скорее доверяю & 10 & 41 & 64 & 66 \\
\hline Скорее не доверяю & 44 & 33 & 5 & 1 \\
\hline Полностью не доверяю & 35 & 7 & 1 & 0 \\
\hline Затрудняюсь ответить & 6 & 12 & 17 & 1 \\
\hline
\end{tabular}

Опрос «Региональный социальный капитал в условиях кризиса». Июнь 2016 г. 
В выделенных на основе индекса доверия группах отношение к президенту неоднозначно. Обращает на себя внимание высокий уровень недоверия в группах с низким доверием и фактически отсутствие недоверия в группах с более высоким значением индекса. Фактически здесь мы наблюдаем поляризацию настроений в отношении данного института, что отражает во многом противоречивую по своему характеру ситуацию в стране.

Таблица 7

Распределение ответов на вопрос

«Насколько Вы доверяете или не доверяете губернатору области?», процент от числа ответивших

\begin{tabular}{l|c|c|c|c}
\multirow{2}{*}{\multicolumn{1}{c|}{ Вариант ответа }} & \multicolumn{5}{c}{ Типы доверия } \\
\cline { 2 - 5 } & $\mathbf{1}$ & $\mathbf{2}$ & $\mathbf{3}$ & $\mathbf{4}$ \\
\hline Полностью доверяю & 0 & 1 & 3 & 17 \\
\hline Скорее доверяю & 0 & 14 & 46 & 79 \\
\hline Скорее не доверяю & 37 & 55 & 22 & 2 \\
\hline Полностью не доверяю & 61 & 16 & 3 & 0 \\
\hline Затрудняюсь ответить & 1 & 15 & 26 & 2 \\
\hline
\end{tabular}

Опрос «Региональный сочиальный капитал в условиях кризиса». Июнь 2016 г.

Губернатор, представляя собой фактически институт исполнительной власти, ассоциируется на региональном уровне с властью вообще. В более ограниченных, по сравнению со страной, масштабах региона усиливается фактор личностного восприятия его руководителя. Тем более что региональная и местная власть несут ответственность за состояние дел в месте проживания респондентов. Значение персонального восприятия особенно велико в Вологодской области. Факты биографии тесно связывают губернатора с самым крупным предприятием области - ПАО «Северсталь» и с г. Череповцом, являющимся крупным промышленным центром Северо-Запада, мэром которого был ныне действующий губернатор. С этим во многом связаны более контрастные оценки, демонстрирующие отношение населения к губернатору. Мы наблюдаем достаточно низкий уровень доверия во всех выделенных нами группах респондентов. Однако, в отличие от института президента, здесь поляризация позиций более заметна как среди тех, кто склонен к доверию, так и среди тех, кто склонен не доверять, т.е. во 2-й и 3-й группах респондентов. Это говорит нам не только о более критичном восприятии региональной власти, но и о ее значении в жизни жителей области. Аналогичная ситуация была выявлена и по отношению к другим институтам власти. Отмеченные различия имеют место и на федеральном уровне, и на уровне региона.

Именно поэтому сознание результатов функционирования политических институтов во многом проявляет себя в характере социальных настроений граждан. Социальное настроение мы рассматриваем как индикатор, характеризующий 
прежде всего степень удовлетворенности человека различными сторонами своей жизни. Данное состояние определяется уровнем экономического благополучия, ощущением защищенности от различных рисков, порождаемых процессами трансформации, во многом являясь результатом самоидентификации (табл. 8)

Таблица 8

Распределение ответов на вопрос

«Что вы можете сказать о своем настроении в последние дни?», процент от числа ответивших

\begin{tabular}{l|c|c|c|c}
\multirow{2}{*}{\multicolumn{1}{c|}{ Вариант ответа }} & \multicolumn{5}{|c}{ Типы доверия } \\
\cline { 2 - 5 } & $\mathbf{1}$ & $\mathbf{2}$ & $\mathbf{3}$ & $\mathbf{4}$ \\
\hline $\begin{array}{l}\text { Эмоциональный подъем, } \\
\text { бодрость }\end{array}$ & 9 & 7 & 9 & 18 \\
\hline Обычное, ровное & 52 & 58 & 69 & 63 \\
\hline Тревожность, раздражение & 27 & 24 & 14 & 9 \\
\hline Безразличие, апатия & 8 & 7 & 4 & 1 \\
\hline Затрудняюсь ответить & 4 & 4 & 5 & 9 \\
\hline
\end{tabular}

Опрос «Региональный социильный капитал в условиях кризиса». Июнь 2016 г.

Приведенные в таблице данные показывают очевидную взаимосвязь доверия и социального настроения респондентов. Низкий уровень в большей степени коррелирует с тревожностью и раздражительностью, безразличием и апатией. Есть определенные различия и в выборе альтернативы «обычное, ровное». Роль социального настроения в поведении человека выражается прежде всего в его регуляторной функции. Социальное настроение может быть выражено в различных формах активности или пассивности личности. Представляя собой комплексное внутреннее состояние индивида, социальной группы или общества в целом, социальное настроение выступает как интегральный показатель удовлетворенности жизнью в социуме, уверенности в будущем, состояния социальной комфортности в отдельном регионе.

\section{Выводы}

Категория доверия характеризует состояние социальных отношений, являясь их основой. Доверие, будучи многоаспектным явлением, подвержено влиянию множества различных факторов как эндогенного, так и экзогенного характера. С одной стороны, оно формируется под влиянием факторов социализирующего характера, являющихся значимыми прежде всего для межличностного доверия, которое, в свою очередь, выступает основой его институциональной формы. Эти факторы мы рассматриваем как факторы микроуровня. К ним относятся такие характеристики, как пол, возраст, образование. Данный перечень может быть расширен. В совокупности они формируют индивидуальный жизненный опыт. На макроуровне влияние на формирование доверия оказывают состояние экономики, материальное благо- 
получие. Принимаемые на уровне властных структур решения могут вызывать как позитивную, так и негативную реакцию населения. Это находит отражение в социальных настроениях, которые, в свою очередь, тесно связаны с доверием.

Использование индикаторного метода позволило выявить группы респондентов, различающиеся по уровню доверия. Принадлежность респондента к той или иной группе во многом определяется социализирующими факторами, определяющими его жизненную позицию, установку на общение, на отношения с окружающей его социальной реальностью. Понимание механизма формирования доверия, выявление влияющих на него факторов дает возможность выстраивать социальную политику, принимать управленческие решения таким образом, чтобы обеспечивать укрепление доверия социальным институтам, и в первую очередь институтам власти, позволяет выстраивать социальное управление в необходимом ключе. Тем самым обеспечивается укрепление социальных отношений.

\section{БИБЛИОГРАФИЧЕСКИЙ СПИСОК}

Алексеева А. Уверенность, обобщенное доверие и межличностное доверие: критерии различения. Социальная реальность, 2008, №. 7, 85-98.

Антоненко И.В. Интегративный потенциал доверия: метаотношения и функции. Вестник Университета (Государственный университет управления), 2012, №. 1, 104-108.

Гидденс Э. Последствия современности. М.: Праксис, 2011.

Глушко И.В. Социальное доверие в контексте межличностных отношений. Историческая и социально-образовательная мысль, 2014, №. 2, 213-216.

Гудков Л. Доверие в России: смысл, функции, структура. НЛО, 2012, №. 117.

Гужавина Т.А. Социальное доверие в гражданском обществе. Проблемы развития территории, 2012, No. 6, 115-122.

Давыденко В.А., Ромашкин Г.С. Системное доверие как фундаментальное условие функционирования и развития общества. Научный потенциал регионов на службу модернизации. Астрахань, 2011.

Заболотная Г.М. Феномен доверия и его социальные функции. Вестник РУДН. Сер. Социология, 2003, №. 4-5, 67-73.

Ильин Е.П. Психология доверия. СПб.: Питер, 2013.

Кертман Г. Межличностное доверие в России. Социальная реальность, 2006, №. 4, 7-24.

Купрейченко А.Б. Психология доверия и недоверия. М.: Институт психологии РАН, 2008.

Кученкова А.В. Межличностное доверие в российском обществе. Социологические исследования, 2016, No. 1, 26-36.

Лапин Н.И. Проблема формирования современного социального порядка в России. Вопросы философии, 2006, No. 11, 3-13. 
Селигмен А. Проблема доверия. М.: Идея-пресс, 2002. 200с.

Татарко А.Н. Межличностное доверие как фактор социально-экономического развития. Социальная психология и общество, 2014, No. 3, 28-41.

Фукуяма Ф. Доверие: социальные добродетели и путь к процветанию. М.: АСТ, 2004.

Шабунова А.А., Гужавина, Т.А., Кожина, Т.П. Доверие и общественное развитие в России. Проблемы развития территории, 2015, №. 2, 7-19.

Штомпка П. Доверие - основа общества. М.: Логос, 2012.

Arrow K.J. The Limits of Organization. New York: Norton, 1974.

Coleman J. Foundations of Social Theory. Cambridge, MA: Harvard University Press, 1990.

Dasgupta P. Trust as a Commodity // Trust: Making and Breaking Cooperative Relations / Diego Gambetta Ed. Oxford, UK: Basil Blackwell. 1988.

Diamond L. Developing Democracy: Toward Consolidation. Baltimore: Johns Hopkins University Press. 1999.

Dryzek J., Stephen T. Leonard Eds. Cambridge, UK: Cambridge University Press. 1995.

Luhman N. Familiarity, Confidence, Trust: Problems and Alternatives. In: Trust: Making and Breaking Cooperative Relations (electronic edition). Ed. by D. Gambetta. Oxford: University of Oxford, 2000.

Orren K., Skowronek S. Order and Time in Institutional Study: A Brief for the Historical Approach. In: Political Science in History / James Farr, John S. Dryzek, and Stephen T. Leonard Eds. Cambridge, UK: Cambridge University Press. 1995.

Shepsle K. Studying Institutions: Some Lessons from Rational Choice Theory. In: Political Science in History / James Farr, John S. Dryzek, and Stephen T. Leonard Eds. Cambridge, UK: Cambridge University Press. 1995.

Stark D. Not by Design: The Myth of Designer Capitalism in Eastern Europe. In: Strategic Choice and Path-Dependency in Post-Socialism / J. Housner, B. Jassop, and K. Nelsen Eds. Aldershot, UK: Edward Elgar. 1995.

\section{REFERENCES}

Alekseeva, A. (2008). Uverennost', obobshchennoe doverie i mezhlichnostnoe doverie: kriterii razlicheniya [Confidence, generalized trust and interpersonal trust: criteria of distinction]. Social'naya real'nost', no 7, 85-98.

Antonenko, I.V. (2012). Integrativnyj potencial doveriya: metaotnosheniya i funkcii [Integrative potential of trust: meta-relations and functions]. Vestnik Universiteta (Gosudarstvennyj universitet upravleniya), no 1, 104-108.

Giddens, A. (2011). Posledstviya sovremennosti [Consequences of modernity]. Moscow: Praksis.

Glushko, I.V. (2014). Social'noe doverie v kontekste mezhlichnostnyh otnoshenij [Social trust in the context of interpersonal relations]. Istoricheskaya i social'no-obrazovatel'naya mysl', no 2, 213-216. 
Gudkov, L. (2012). Doverie v Rossii: smysl, funkcii, struktura [Trust in Russia: meaning, functions, structure]. NLO, no 117.

Guzhavina, T.A. (2012). Social'noe doverie v grazhdanskom obshchestve [Social trust in civil society]. Problemy razvitiya territorii, vol. 62, no 6, 115-122.

Davydenko, V.A., Romashkin, G.S. (2011). Sistemnoe doverie kak fundamental'noe uslovie funkcionirovaniya i razvitiya obshchestva [System trust as fundamental condition for functionnung and development of society]. Nauchnyj potencial regionov na sluzhbu modernizacii. Astrahan', 166-172.

Zabolotnaya, G.M. (2003). Fenomen doveriya i ego social'nye funkcii [Phenomenon of trust and its social functions]. Vestnik RUDN, Sociology Series, 4, no 4-5, 67-73.

Il'in, E.P. (2013). Psihologiya doveriya [Psychology of trust]. SPb.: Piter.

Kertman, G. (2006). Mezhlichnostnoe doverie v Rossii [Interpersonal trust]. Social'naya real'nost', no 4, 7-24.

Kuprejchenko, A.B. (2008). Psihologiya doveriya i nedoveriya [Psychology of trust and distrust]. Moscow: Institute of Psychology of the RAS.

Kuchenkova, A.V. (2016). Mezhlichnostnoe doverie v rossijskom obshchestve [Interpersonal trust in the Russian society]. Sociologicheskie issledovaniya, no 1, 26-36.

Lapin, N.I. (2006). Problema formirovaniya sovremennogo social'nogo poryadka v Rossii [Issue of formation of contemporary social order in Russia]. Voprosy filosofii, no 11, 3-13.

Seligmen, A. (2002). Problema doveriya [Issue of trust]. M.: Ideya-press.

Tatarko, A.N. (2014). Mezhlichnostnoe doverie kak faktor social'no-ekonomicheskogo razvitiya [Interpersonal trust as a factor of social-economic development]. Social'naya psihologiya i obshchestvo, no 3, 28-41.

Fukuyama, F. (2004). Doverie: social'nye dobrodeteli i put' $k$ procvetaniyu [Trust: The social virtues and the creation of prosperity]. Moscow: AST; Ermak.

Shabunova, A.A., Guzhavina, T.A., Kozhina, T.P. (2015). Doverie i obshchestvennoe razvitie v Rossii [Trust and social development in Russia]. Problemy razvitiya territorii, no 2, 7-19.

Shtompka, P. (2012). Doverie - osnova obshchestva [Trust — a basis of society]. Moscow: Logos.

Arrow, K.J. (1974). The Limits of Organization. New York: Norton.

Coleman, J. (1990). Foundations of social theory. Cambridge, MA: Harvard University Press.

Dasgupta, P. (1988). Trust as a Commodity. In: D. Gambetta (Ed.) Trust: Making and Breaking Cooperative Relations (pp. 49-72). Oxford, UK: Basil Blackwell.

Diamond, L. (1999). Developing Democracy: Toward Consolidation. Baltimore: Johns Hopkins University Press.

Dryzek, J., Leonard, S.T. (1995). History and discipline in Political Science. Cambridge, UK: Cambridge University Press. 
Luhman, N. Familiarity, Confidence, Trust: Problems and Alternatives. In: D. Gambetta (Ed.) Trust: Making and Breaking Cooperative Relations (pp. 94-107). Oxford, UK: Basil Blackwell.

Orren, K., Skowronek, S. (1995). Order and time in institutional study: A brief for the historical approach. In: Political science in history, / James Farr, John S. Dryzek, and Stephen T. Leonard Eds. Cambridge, UK: Cambridge University Press.

Shepsle, K. (1995). Studying institutions: some lessons from the rational choice theory. In: Political science in history, / James Farr, John S. Dryzek, and Stephen T. Leonard Eds. Cambridge, UK: Cambridge University Press.

Stark, D. (1995). Not by Design: The Myth of Designer Capitalism in Eastern Europe. In: Hausner J., Jessop B., Nielson K., editors. Strategic Choice and Path Dependence in Post-Socialism. Aldershot, UK: Edward Elgar. 